\section{Postnatally-Acquired COVID-19 in Central India}

Severe acute respiratory syndrome coronavirus 2 (SARS-CoV2) infections have achieved pandemic proportions; although, pediatric manifestations still remain poorly delineated [1]. We describe two infants with postnatally acquired SARS-CoV-19 infection and discuss pertinent issues.

A 21-day-old girl was admitted with history of tachypnea for 1 day. She was born at 39 weeks of gestation with a birth weight of $3000 \mathrm{~g}$ to a primigravida mother who had an uneventful antenatal history. On admission, the temperature was $36.5^{\circ} \mathrm{C}$, with pulse 140 beats per minute and respiratory rate 60 breaths per minute (oxygen saturation $90 \%$ in room air). Chest radiograph showed bilateral diffuse infiltrates. Laboratory investigations revealed hemoglobin of $11.1 \mathrm{~g} / \mathrm{dL}$, total leukocyte count 15,700/cumm (polymorphs 26\%, lymphocytes 55\%), platelets $6.69 \times 10^{9} / \mathrm{L}$, alanine transaminase $28 \mathrm{IU} / \mathrm{L}$, serum ferritin $178 \mathrm{ng} / \mathrm{mL}$, lactate dehydrogenase (LDH) $320 \mathrm{U} / \mathrm{L}$ and C-reactive protein (CRP) $0.5 \mathrm{mg} / \mathrm{dL}$. Her nasal swab Reverse transcriptase polymerase chain reaction (RT-PCR) was positive for SARS-CoV-2. On contact tracing, the father and paternal grandfather were reported to be positive for SARS-CoV-2.

A 2-and-a-half-month-old boy was admitted with history of fever for two days. Neonatal period was uneventful and he was exclusively breastfed. At admission, his pulse rate was $112 / \mathrm{min}$, respiratory rate of $52 / \mathrm{min}$ and oxygen saturation in room air of $88 \%$. His chest radiograph showed right sided infiltrates. Laboratory investigations showed hemoglobin 9.8 $\mathrm{g} / \mathrm{dL}$, total leucocyte count $6710 / \mathrm{cu} \mathrm{mm}$ (polymorphs $24 \%$, lymphocytes $66 \%$ ), platelets $4.5 \times 10^{9} / \mathrm{L}$, alanine aminotransferase $23 \mathrm{IU} / \mathrm{dL}$, and CRP $0.5 \mathrm{mg} / \mathrm{dL}$. His nasal swab RT-PCR for SARS-CoV-2 tested positive on the day of admission. His grandfather had recently tested positive for SARS-CoV-2. However, his parents and other family members were negative for the infection.

Both the infants received oxygen, broad spectrum antibiotics and syrup azithromycin $(10 \mathrm{mg} / \mathrm{kg} /$ day $)$ and syrup oseltamivir ( $3 \mathrm{mg} / \mathrm{kg} /$ day in two divided doses). None of the patients required ventilation. Both the infants were nursed by their mothers during hospital stay and were exclusively breastfed. Mothers were taught about the careful disposal of diapers and hand hygiene before and after handling the infants. There was no transmission of infection and nasal swabs for
RT-PCR for SARS-COV-2 were negative for each mother twice. The babies were discharged home without supplemental oxygen after two repeat samples were negative.

The cases are presented to highlight the importance of mutual transmission of disease between mother, infant and other caregivers in the family. Infection was suspected in both infants based on clinical presentation and family history of infection in one or more family members. Recent research has shown that apart from droplets, infection can be transmitted through saliva of the infant [2] during breastfeeding, and stool of the infant [3-5], as viral shedding continues for several weeks in neonates. However, breastfeeding needs to be continued as per current recommendations [6], with regular hand washing with soap and water and proper diaper disposal. The presented cases signify the importance of proper hygiene in preventing transmission of infection from infected infants to nursing mothers, caregivers and vice versa.

Published online: July 07, 2020; PII: S097475591600206

Jenisha JAIN* AND SHIKHAR JAIN Department of Pediatrics Choithram Hospital and Research Centre, Indore, Madhya Pradesh, India. *tojenisha@gmail.com

\section{REFERENCES}

1. Balasubramanian S, Rao NM, Goenka A, Roderick M, Ramanan AV. Coronavirus disease 2019 (COVID-19) in children - What we know so far and what we do not. Indian Pediatr. 2020;57:435-42.

2. Xu R, Cui B, Duan X, Zhang P, Zhou X, Yuan Q. Saliva: Potential diagnostic value and transmission of 2019nCoV. Int J Oral Sci. 2020;12:11.

3. Xing YH, Ni W, Wu Q, Li WJ, Li GJ, Wang WD, et al. Prolonged viral shedding in feces of pediatric patients with coronavirus disease 2019. J Microbiol Immunol Infect. 2020;53:473-80.

4. Ma X, Su L, Zhang Y, Zhang X, Gai Z, Zhang Z. Do children need a longer time to shed SARS-CoV-2 in stool than adults? J Microbiol Immunol Infect. 2020;53:373-76.

5. Wu Y, Guo C, Tang L, Hong Z, Zhou J, Dong X, et al. Prolonged presence of SARS-CoV-2 viral RNA in faecal samples. Lancet Gastroenterol Hepatol. 2020;5:434-35.

6. Chawla D, Chirla D, Dalwai S, Deorari AK, Ganatra A, Gandhi A, et al. Perinatal-Neonatal Management of COVID-19 Infection - Guidelines of the Federation of Obstetric and Gynecological Societies of India (FOGSI), National Neonatology Forum of India (NNF), and Indian Academy of Pediatrics (IAP). Indian Pediatr. 202;57: 536-48. 